\title{
A LONG-TERM FOLLOW-UP OF THORACOPLASTY CASES
}

BY

\author{
F. RONALD EDWARDS, G. LEGGAT, AND H. MORRISTON DAVIES \\ From the Liverpool Thoracic Surgical Centre, Broadgreen Hospital, and High Carley Sanatorium, Ulverston
}

(RECEIVED FOR PUBLICATION JANUARY 24, 1953)

In 1941 we published an article in the British Medical Journal on the treatment of pulmonary tuberculosis by thoracoplasty, which was illustrated by a consecutive series of operations undertaken by us at High Carley Sanatorium between 1933 and 1940. We have reviewed this group of thoracoplasties recently (December, 1952), and as a matter of general interest present the results herewith, giving a 12-19-year follow-up study. There were 59 cases in the original publication, and all have been followed up to date except one; this patient was, however, known to be fit and well and working two years ago, i.e., 15 years after operation.

The type of operation used was a 10-rib thoracoplasty with removal of transverse processes. No apicolysis was performed. This operation gave a very complete lateral collapse of the lung, but scoliosis was frequently marked.

Our tenets for selecting cases for thoracoplasty as given in our original publication would still apply to-day, but it will be seen (Fig. 1) that the type of case we then submitted to this operation had a very severe form of disease with much destruction of lung substance. This type of case is much more rarely seen to-day owing to the advent of chemotherapy.

Fifty-two cases had parenchymatous disease and in a further seven there was an overlying empyema.

Seven patients died within three months of the operation, giving a post-operative mortality rate of $12 \%$.

\section{FolLOW-UP}

Patients with Empyema. - Of seven cases, three died within three months (Nos. 53, 55, 59), one died at nine months (No. 58), one died two years later with contralateral spread (No. 54), and two are alive and well.

Patients with Parenchymatous Disease.-Of 52 cases, 22 have died of pulmonary tuberculosis $(42 \%)$, and one died of carcinoma of the cervix 13 years after her operation. She was well from the chest point of view (No. 12). Twenty-nine (56\%) are alive ( 27 are very well, two not so well, but all are free of tubercle bacilli in the sputum).

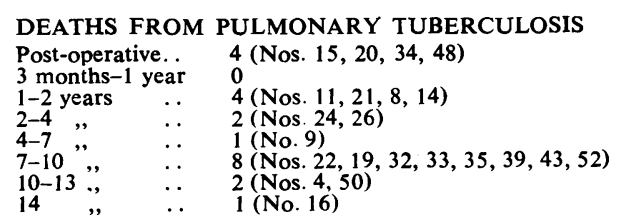

It is interesting to note that of the 22 deaths, 11 occurred seven years or more after the operation. This only emphasizes once more that in the assessment of any form of treatment of such a chronic infection as tuberculosis of the lungs, the followup must be a very long one.

Seven patients were discharged from the sanatorium with a positive sputum. Six (Nos. 24, 26, $35,39,43$, and 46 ) of these are dead, and one (No. 6) is not so well now.

Eleven patients (see diagram) were noted to have some crepitations on the opposite side before the operation, but no very obvious radiological evidence of disease. All these patients are now dead except one (No. 44), who is reasonably well.

We assessed our cases into two groups: (1) good risk, and (2) justifiable risk. The present position of these patients is as follows:

\begin{tabular}{|c|c|c|c|c|}
\hline & & $\begin{array}{l}\text { No. of } \\
\text { Cases }\end{array}$ & Dead & Alive \\
\hline $\begin{array}{l}\text { Good risk .. } \\
\text { Justifiable risk }\end{array}$ & & 40 & $\begin{array}{c}13(32 \cdot 5 \%) \\
(1 \text { of unrelated cause }) \\
9(75 \%)\end{array}$ & $\begin{array}{r}26 \\
3\end{array}$ \\
\hline
\end{tabular}

SUMmary

A consecutive series of 59 thoracoplasties undertaken 12 to 19 years ago have been followed up. $c$ Twenty-seven patients $(46 \%)$ have died of pul- $\frac{\mathscr{D}}{\mathscr{}}$ monary tuberculosis. Fifty-two of the thora- ? coplasties were for parenchymatous disease; of 0 these cases 22 patients have died of pulmonary tuberculosis. Fifty per cent. of these deaths $\stackrel{D}{\Omega}$ occurred seven or more years after the operation. $\mathbb{D}$

REFERENCE

Edwards, F. R., Leggat, G., and Davies, H. Morriston 1941). Brit. med. J., 2, 901 . 


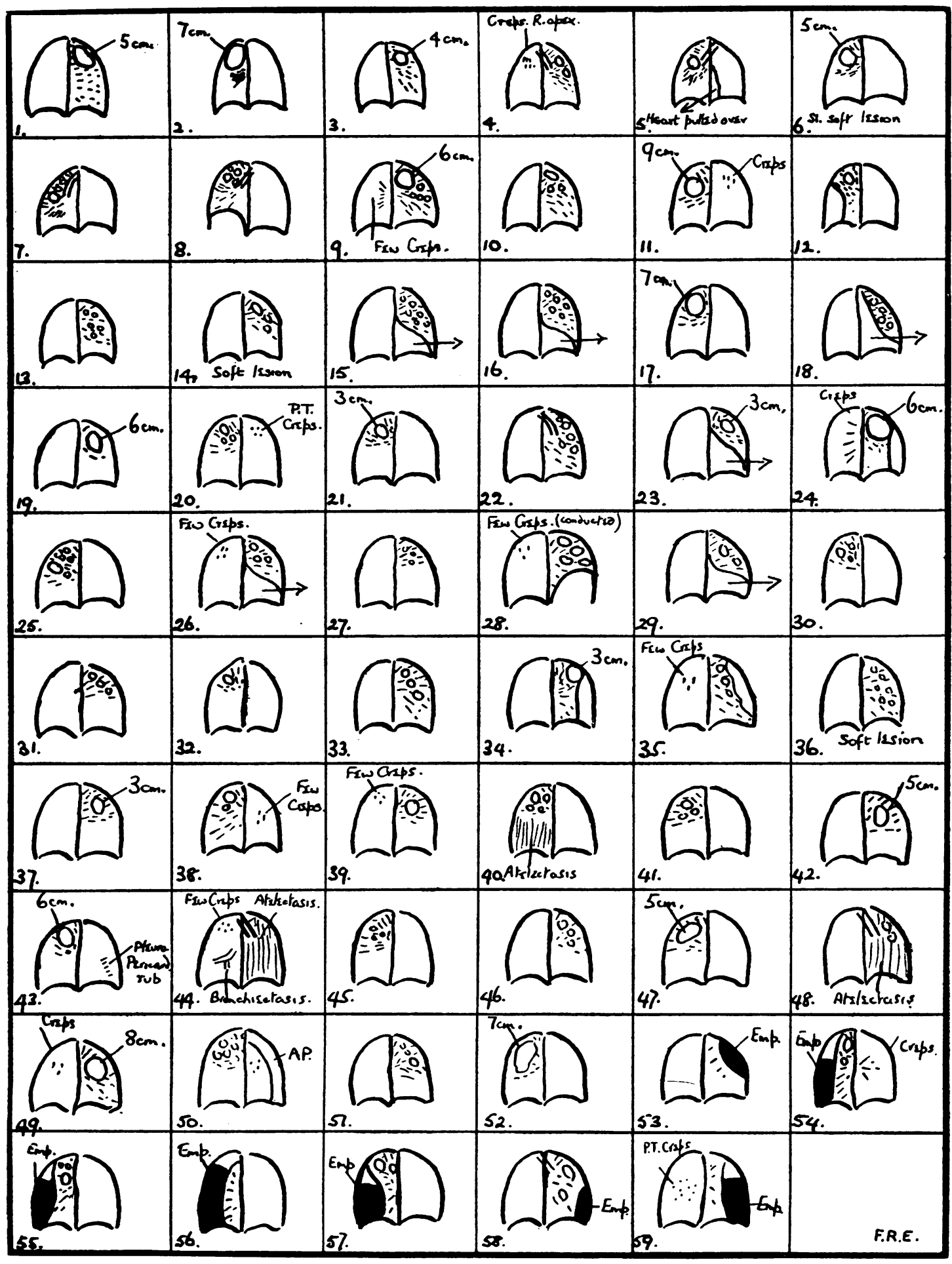

